\title{
A ultrapassagem das fronteiras: hibridismo e universalismo na obra de Laura Erber
}

Alva Martínez Teixeiro ${ }^{1}$ Tout ce qui était n'est plus; tout ce qui sera n'est
pas encore. Ne cherchez pas ailleurs le secret de
nos maux

Alfred de Musset

A palavra é a minha quarta dimensão

Clarice Lispector

A pretensão central deste trabalho é analisar criticamente duas das obras literárias da escritora, artista visual e professora Laura Erber (Rio de Janeiro, 1979), como exemplo paradigmático do entrecruzamento de três tendências significativas da literatura brasileira dos últimos anos: a revitalização do denominado cross genre e, de modo complementar, a atualização do grande tema literário da viagem e dos diálogos culturais, assim como a renovação de uma certa escrita do eu.

Com esse objetivo, selecionei duas obras da poliapta criadora, Bénédicte vê o mar (2011) e Esquilos de Pavlov (2013), que refletem o modo como essa autora amplia os caminhos da literatura ao entrecruzá-la com outros discursos, como o plástico, o fotográfico, o cinematográfico ou o ensaístico, testemunhando e mesmo contaminando a sensibilidade de uma época num modelo total, difuso e omnívoro de escrita - modelo, aliás, articulado em torno da dúvida e do questionamento a respeito da arte contemporânea. Uma indagação, pois, que lhe permite estabelecer um diálogo cultural que ultrapassa as fronteiras do nacional para situar-se num plano universal, graças ao poder ecumênico da dúvida: no momento de transição vivido na contemporaneidade, em que o velho não foi ainda totalmente enterrado e o novo não foi imposto ainda de modo definitivo, tendo-se esgotado o poder de negação e a potência de afirmação da resposta, Erber opta pela resposta provisória que intensifica a pergunta, a faz

1 Doutora em literatura brasileira e professora auxiliar de literatura e cultura brasileira da Universidade de Lisboa, Lisboa, Portugal. E-mail: alvamteixeiro@ campus.ul.pt 
durar e a aguça, isto é, pela resposta interrogativa de que falava Maurice Blanchot (1990, p. 33).

Ambas as obras carregam questões, sendo elas mesmas questionamentos, ao assumir um caráter propositadamente inquiridor, aberto e instigante, que nos permite aproximá-las da literatura de proposta ou exigente, de acordo com a conhecida designação estabelecida pela professora Leyla Perrone-Moisés (2012) e radicalmente divergente da homogeneizadora leitura da literatura brasileira contemporânea, condensada no conceito de hiper-mimetismo, proposto por Alfredo Bosi (2002, p. 251), no ensaio "Os estudos literários na era dos extremos", segundo o qual, desde a década de 1970, teriam surgido uma literatura e uma crítica subalternas, atentas aos interesses dos diversos e estereotipados grupos de público: feminista, de minorias étnicas, ecológico, terceiro-mundista etc.

Por oposição a essa visão ironicamente empobrecedora do panorama literário atual, especialistas como Leyla Perrone-Moisés ou Jaime Ginzburg valorizam a busca levada a cabo por diversos escritores à procura de uma enunciação criativa e divergente da tradição realista. Assim, a professora paulistana retratava em 2012 uma nova geração de excelentes narradores, herdeiros da complexidade das vanguardas do século XX e cujos livros "não dão moleza ao leitor; exigem leitura atenta, releitura, uma bagagem razoável de cultura, alta e pop, para partilhar as referências explícitas e implícitas" (Perrone-Moisés, 2012, p. 5), enquanto, no mesmo ano, o professor da Universidade de São Paulo afirmava:

Contrariamente à hipótese do hiper-mimetismo, gostaria de perseguir, a partir da ideia de hibridismo de gêneros, e de uma situação diferenciada para a literatura brasileira em contatos com gêneros considerados não literários, a ideia de que está presente de modo constante na produção contemporânea um procedimento anti-mimético. Diversos escritores estariam se distanciando da ideia tradicional de representação, em favor de perspectivas novas - para as quais a crítica ainda está constituindo um vocabulário com que precisa trabalhar (Ginzburg, 2012, p. 214).

No caso das obras de Laura Erber, essa transgressão das convenções mais tradicionais da representação deriva, como dizia, do recurso à dúvida. Nesse sentido, a primeira e mais evidente dúvida que suscitam tem a ver com a apreciação formal, pois, numa resposta provisória à questão da 
obsolescência das antigas convenções, ambas partem desses consabidos princípios pós-modernos da revisão do cânone e do hibridismo e, portanto, as duas avisam os seus leitores de que, no sentido referido por Jaime Ginzburg, o problema das classificações genéricas canônicas reside no fato de nem todos os textos serem abrangidos hoje por elas.

Bénédicte vê o mar é um texto com forte molde individualista, que reúne o diálogo de vários gêneros num longo e estranho poema narrativo, com uma incomum narratividade, em que a história que está sendo contada - a de uma autora, Bénédicte, que sofre um bloqueio criativo - é filtrada por uma discursividade poética e uma linguagem figurada de notável concentração, intensidade e ambiguidade. Trata-se, portanto, de um texto com sua própria voz, graças também ao verso livre de teor irregular, delineado como negação de qualquer padrão estandardizado e, consequentemente, como valorização da excêntrica inventio de uma autora que, à procura do inusitado e das margens do poético, hipertrofia algumas das caraterísticas do gênero, nomeadamente a ludicidade presente nos jogos sonoros e de sentido semeados no fluido decorrer do texto.

Por seu turno, Esquilos de Pavlov ultrapassa essa ambiguidade inicial, optando pelo gênero romanesco, uma opção que poderíamos considerar uma espécie de legitimação e validação $a$ posteriori da maestria da autora: se me permitirem a analogia, com a publicação desse romance, Erber tornar-se-ia, depois da experimentalidade intensa da obra anterior, uma autora confiável para o leitor e o crítico convencionais, como sucede ao pintor moderno em quem depositamos o nosso respeito e confiança porque sabemos que sabe pintar à maneira tradicional. No entanto, essa viragem formal não representa uma guinada conservadora do ponto de vista escritural, senão uma certa continuidade, pois, à sua maneira, o romance é mais provocador e questionador que Bénédicte vê o mar.

É um romance de formação de artista, mas trata-se de um romance irônico, sofisticado e melancólico - pois, acabamos por compreender que a formação do protagonista consiste, na verdade, na gradativa libertação de todo o aprendido a respeito do mundo da arte ou, inclusive, na paradoxal travessia para se converter numa espécie de resistente artiste sans oeuvre, tipologia sobre a qual, de maneira lúcida, dissertou Jean-Ives Jouannais, em obra assim intitulada (2009). Trata-se também de um romance do desaprender, dotado de uma admirável liberdade de tom e de allure e de uma compreensão profunda dos desafios romanescos, postas a serviço de um pensamento inquiridor e permanentemente 
insatisfeito com as convenções do mundo da arte, quer no plano social, quer no plano criativo.

É assim que a prática metaficcional e, de modo mais geral, a autoconsciência artística - e não apenas escritural - presentes na obra evocam a idealização, tal como proposta por Linda Hutcheon, ao definir a metaficção como narcísica, não num sentido depreciativo, senão sugestivo, como o das leituras alegóricas do mito de Narciso (Hutcheon, 1984, p. 1). A reflexão metanarrativa, entendida como um mecanismo para pôr a descoberto o arcabouço da ficção - iluminado por uma ironia com propósitos regeneradores -, critica pontualmente alguns dos alicerces desse romance de (de)formação, como demonstra a cáustica apreciação, exposta no início do romance, da escolha de um discurso enunciado na primeira pessoa:

Uma pessoa a quem tive intenção de contar a minha história disse que somente duas situações justificariam o relato em primeira pessoa: morte próxima ou indiferença total em relação aos pronomes. Não sei bem o que quis dizer, mas sei que tentava me persuadir a desistir (Erber, 2013, p. 14).

A comparação sumária das duas obras revela uma falta de compromisso com um gênero, estilo ou técnica determinados, sem que tal nos permita adivinhar qualquer poética da profusão baseada no princípio do "tudo é possível", porque, como dizia, existe uma continuidade entre os dois textos, baseada no caráter indagador de ambas as obras, sustentado por um hibridismo genérico partilhado, pois elas nos revelam uma arte que tende a absorver em si o papel da crítica. Uma crítica, digase também, que, levada ao seu extremo, é tão construtiva que gera os objetos artísticos, em vez de ser produzida por eles: o centro e o tema de ambos os livros é a criação - e suas possibilidades, suas impossibilidades e seus atritos - dos protagonistas.

Nesse sentido, resulta interessante e significativo verificar que, em nossa época, autores historicistas - e essencialistas - como o professor Arthur Danto falem do fim da arte enquanto grande narrativa, enquanto processo gradativo de consecução de uma consciência crescente de seus meios. Segundo o autor norte-americano, esse processo não constitui a morte da arte, mas, sim, a da sua história, que o filósofo e crítico, significativamente, compara a um romance de formação: em sua análise, a vida adulta da arte começa quando sua formação termina. Pois bem, resulta significativo e interessante, dizíamos, nesse sentido problematizador quanto aos meios, 
possibilidades, convenções e supostos progressos, o fato de Erber escolher como protagonista desse romance um confuso, indócil e inoportuno artista em formação e como molde narrativo um romance de (de)formação. E ao focar a narrativa, resulta relevante, em especial, esse momento atual, no qual a arte, autorreflexiva a respeito de como representar - não o mundo, mas a própria arte -, deixa de impor limites a si própria, gerando a consequente dificuldade de discernimento entre o verdadeiro artista (e/ou a verdadeira arte) e a impostura, tema fundamental em Esquilos de Pavlov.

A autora se mostra afinal, em ambas as obras, como uma escritora descrente da eficácia isolada dos gêneros literários, mas também das linguagens artísticas, pois Bénédicte vê o mar pode ser classificado, ainda, como uma poesia gráfica e reflexiva a respeito da criação artística, enquanto Esquilos de Pavlov pode ser apreendido através das fotografias que pretendem convulsionar a narrativa tradicional.

Nessa obra híbrida, a influência da artista bifronte não se materializa apenas na escrita sobre as artes visuais, senão no entrecruzamento da ficção narrativa e da ficção fotográfica. Erber privilegia a fotografia como expressão da metafísica moderna e, partindo da concepção de Barthes, que a considera como "análogo da realidade", elabora múltiplas estratégias de interação, do mais convencional suplemento plástico-artístico e espacial, oferecido pelas artes visuais à literatura, à descontinuidade transgressora instaurada dentro das páginas do livro, graças a certas fotografias selecionadas aleatoriamente - ou descolocadas - como parte da obra, pois lembremos, a autora é mais uma cultivadora da estranheza.

A título de exemplo, podemos lembrar da discordância entre a fotografia de uma iguana e a abertura do romance no qual se insere e em que o protagonista, Ciprian Momolescu, diz:

Minha ficção de origem começa na ala esquerda de um hospital azul por dentro. É o início de uma nova década e dizem que a pintura vai acabar. Dizem que a nova beleza está na forma das cidades e no rosto das pessoas. E dos carros. Enquanto isso, na Califórnia, uma dona de casa na curva dos sessenta entra num supermercado e dispara sobre crianças e potes de picles (Erber, 2013, p. 12-13).

Um exemplo, aliás, que exige uma apreciação - mesmo que seja sucinta e inicial - da presença do estranhamento e do distanciamento como instrumentos literários e estéticos da experiência do mundo presente nas obras, distantes das metáforas gastas e de uma percepção previsível do real. Nelas o espaço social é representado frequentemente como o espaço por 
excelência de negação dos novos ídolos da condição pós-moderna, como espaço da ambivalência e da dupla realidade da sociedade do bem-estar e da sua hipocrisia sistêmica. Trata-se de uma duplicidade que aflige os protagonistas, especialmente Bénédicte que, como veremos, isola-se num microcosmo artístico e existencial artificial, apresentado como um universo distante do mundo real, estranho, anômalo e, mais uma vez, excessivo em sua asséptica violência:

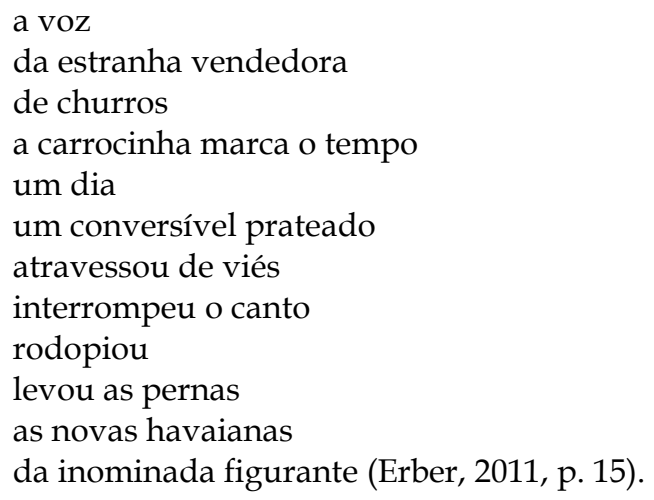

Regressando à questão em apreço, Bénédicte vê o mar, por sua vez, é um livro que nunca foi impresso em papel e que só existe - e, acreditamos, só pode existir plenamente - no mundo digital, porque a autora inventa usos complexos do formato digital, tornando o poema ilustrado um poema animado, de fluidez quase fílmica ou rudimentarmente fílmica, graças ao fluir dos desenhos presentes em muitas das páginas da obra. Erber subverte, assim, as restrições de natureza formal inerentes ao livro tradicional, explorando as possibilidades de leitura verticais e não horizontais, como o artista de vanguarda que transgrediu a convenção do retângulo para a pintura ou qualquer outra convenção arbitrária.

Assim, essa plasticidade quase fílmica da obra complementa e amplifica a linguagem autorreflexiva do próprio poema, focada no bloqueio de Bénédicte, que, como se diz e se mostra, "[g]ostaria de escrever assim" (Erber, 2011, p. 30), mas é condenada temporariamente ao silêncio involuntário, num aflitivo processo de busca, que se move entre a certeza e a esperança da possibilidade, pois "escrever dói / e pode ser divertido" (Erber, 2011, p. 21). Assim, paradoxalmente, faz da causa da impossibilidade de criar a própria matéria da criação. 
Erber considera, portanto, que, num meio dominado em grande medida pela arte conceitual e pela abstração, a pintura figurativa é ainda uma linguagem forte, mas, felizmente, como acontecia com o romance de formação, subvertida e adequada à complexidade e à disfuncionalidade do mundo contemporâneo. E digo isto sublinhando a escolha do advérbio felizmente, porque, como afirma o curador e ensaísta Francesco Bonami, não sem alguma ironia - mas com uma certa e incontornável razão -, não há nada pior para um artista contemporâneo do que estar fora da sincronia sem se ter dado conta (Bonami, 2013, p. 110). Tal não é o caso. Erber procura sempre condições de visibilidade difícil, na fotografia ou no desenho. Mas nem sempre essa dificuldade de compreensão das imagens é conseguida através da obscuridade, como no antes referido exemplo da fotografia da iguana. Por vezes, aquilo que nos impede de apreender a imagem é uma claridade demasiado intensa que, no caso de Bénédicte vê o mar, se traduz na simplicidade desconcertante dos desenhos, figuras reduzidas ao mínimo, oscilando entre o lírico e a comicidade de cartoon (Lemos, 2011, p. 3).

Habituados a perceber a realidade segundo determinados modelos, $\mathrm{o}$ leitor é convidado, como disse anteriormente, a uma experiência estranha, também porque a autora aborda questões graves, como, para só oferecer um exemplo paradigmático, a crise - existencial e criativa -, despindo-os, através do plástico, de tons patéticos ou excessivamente solenes. Numa revolta mais contra o horizonte de espera do público, o infantilismo pictórico serve para condensar o sentimento de perturbação que domina a protagonista, através das cores e da pulsão emotiva das imagens, e para representar a mecânica do mal-estar por meio de um dinamismo que nega a monotonia e a inércia do patético.

Nesse sentido, é de notar que a poética transgressora proposta em ambas as obras se baseia em duas variantes interartísticas módicas, mas significativas, centradas, insistimos, num olhar incomum e alheio à normalidade mundana, tipicamente pós-moderno, mas apenas em termos artísticos, pois, como sabemos, a arte não antecipa as percepções ordinárias do porvir - e podemos lembrar a conhecida reflexão de Gombrich, retomada por Lorenzo Mammì em $O$ que resta: arte e crítica de arte, que afirmou que, em tal caso, os supermercados apresentariam aos clientes os seus produtos em folhetos cubistas.

Destarte, resta-nos apenas referir um último e significativo caso dessa utilização múltipla e cumulativa de gêneros e linguagens 
artísticas presente nas duas obras, pois esse diálogo interartístico está presente também nas próprias histórias, uma vez que Bénédicte supera sua crise realizando um filme e a proposta artística de Ciprian, um jovem "que só era feliz na biblioteca, foi uma espécie de cinéfilo dos livros" (Erber, 2013, p. 49), consiste em realizar instalações nas bibliotecas, fazendo "deslocamentos, rearranjos, trocas de lugar", mediante as quais cria novas vizinhanças e distâncias, por exemplo, entre "os livros que começam por uma pergunta" (Erber, 2013, p. 133).

Desse modo, aproveitando os parâmetros artísticos estabelecidos por Ciprian, pretendemos aproximar os livros, pois eles são presididos por uma pergunta inicial que, em sentido lato, articula as duas obras e nos permite reconstruir melhor as preocupações e obsessões de sua autora, uma vez que o paralelo multiplica as perspectivas de observação do mundo para revelarnos, por repetição e variação, que o olhar é sempre o mesmo.

É assim que, quando Ciprian nasce, no início do romance, o pai lhe diz à maneira de perturbadoras boas-vindas: "Eis o mundo, filho. Será que você cabe? Alguns cabem, outros entalam" (Erber, 2013, p. 13). Pois bem, como dizia, o romance estabelece uma certa continuidade em relação a Bénédicte vê o mar, pois ambas as obras conferem protagonismo a personagens que quebram com o sistema, sujeitos tentados pela inquietação e pela estranheza, cultivada num duplo sentido: a estranheza, como vimos, face ao Outro, mas também a estranheza face à própria subjetividade desordenada.

Esquilos de Pavlov pode também ser lido como um prosseguimento e aprofundamento narrativo de questões apenas expostas na obra poética anterior. Aqui encontramos uma personagem sem passado e sem história tentando lidar com uma crise existencial e criativa, isolando-se e barricando-se no porão de uma marmoraria, enquanto seus pensamentos "gangrenam" (Erber, 2011, p. 11). O leitor situa-se, portanto, perante o mesmo, repetido e teimoso dilema: será que cabe ou entala?

Por seu lado, Bénédicte isola-se, negando, como vimos, um mundo cruel e estranho, "cada vez menos explicável" (Erber, 2011, p. 19) procurando a inspiração da sua musa "perita em exegese / com tendência ao brutalismo" que, com seu silêncio, causa o "síndrome de Não Ver o Mar" (Erber, 2011, p. 26), isto é, o bloqueio. À procura da inspiração e do modelo perfeito de Bénédicte, a obra viaja através de sua vasta enciclopédia cultural, levando o leitor por um território riquíssimo em referências e pensamentos, habitado por personagens de 
Robert Walser e animado pela admiração por Chico Alvim, pela escritora de origem romena Aglaja Veteranyi ou pelos fotógrafos Linka Levedeva e August Sander. Esse procedimento move-se entre a evocadora menção e a citação oblíqua, que conquista o espaço da abertura literária através daquilo que Antoine Compagnon denomina "reescrita", um exercício baseado em duas operações, uma de extirpação e a outra de enxerto (Compagnon, 1979, p. 29), executadas com maestria, produzindo uma textualidade que, entre a inventio e uma complementar apropriação, gera obras que abordam e comentam outras obras literárias e artísticas, isto é, obras que se apresentam como alegorias de alegorias.

Em Bénédicte vê o mar, parece ecoar o ditado de Baudelaire, o primeiro a dizer que cada vez é mais difícil ser um artista sem ser um crítico, acontecendo o mesmo no romance, através, dessa vez, do movimento contrário ao confinamento de Bénédicte: os deslocamentos constantes e errantes do protagonista.

Erber situa retrospectivamente o início do seu romance na infância taciturna de Ciprian Momolescu, um menino inadaptado aos estreitos limites da Romênia de Ceacescu e que conseguirá já adulto enquadrar sua visão do mundo numa moldura mais abrangente.

No romance, são apreciáveis as censuras cáusticas aos princípios do realismo socialista, estilo artístico oficial, cuja finalidade de propaganda totalitária é auxiliada pela escrita pouco entusiasta do pai do protagonista, um escritor que se tinha iniciado nas lides da literatura inspirado pelo surrealismo, mas que, depois de um duro período na prisão, decide sujeitar-se à doutrina dominante. Assim, a obra integra, em primeiro lugar, uma breve, mas impiedosa sátira do ideal de participação ativa na representação, divulgação e exaltação da nova organização da realidade, através da atenção dedicada ao pai, autor da série infantil As aventuras do ursinho metalúrgico, que, como uma despropositada fábula, possui um duvidoso caráter educativo e uma não menos duvidosa e distorcida moral.

A série, protagonizada por um urso metalúrgico, isto é, representante por excelência do bom proletariado em viagem no país, estabelece analogias entre o cotidiano social e as histórias que vivencia. Assim sucede, por exemplo, com o encontro com os esquilos tchecoslovacos hippies "que comiam sem parar e diziam você é um dos nossos, não tenha medo, o tesouro está no campo, no olhar dos bichos, no pôr do sol e nas canções" (Erber, 2013, p. 32), tentando-o em vão com as possibilidades de uma vida 
livre, pois o herói, como convém a um verdadeiro representante do positivismo heroico, despedia-se das promessas de uma vida despojada e soberana para regressar ao seu posto numa fábrica da capital.

Essa ridicularização da idealização da utopia social adquire uma dimensão ironicamente trágica, aliás, quando comparada com o involuntário imobilismo do autor das aventuras do ursinho viajante: Ciprian, em uma das intervenções numa biblioteca de Paris, descobre uma carta do pai, um pedido de ajuda para exilar-se na França. Essa carta contraria a imagem estática de passividade e conformismo que o protagonista tinha criado a respeito do pai, cujas expectativas em relação à vida pareciam satisfeitas com uma biografia parca e a serviço do partido, como a do ursinho, simbolizada no prêmio recebido há muitos anos atrás pelas obras edificantes que escrevia: "dez dias com toda a família no Neptun Resort", uma cidade-hotel no mar Negro, frequentada pela família Ceaucescu, onde "quando eles estavam lá havia carne no menu" (Erber, 2013, p. 21).

O imobilismo forçoso do pai dentro dos mesquinhos e inflexíveis confins existenciais e escriturais - pois implicitamente existe também a censura ao caráter prescritivo dos movimentos e escolas, paradigmática e paroxisticamente representada no romance por esse infeliz epígono da arte soviética - desse espaço que fisicamente habita confere dramático protagonismo à idealização da viagem como fuga. Uma evasão que é retratada, em primeiro lugar, como impossibilidade, através da lembrança do avô de Ciprian, filho de um cartógrafo que percorria a Europa e que alardeava o fato histórico de o pai "ter redesenhado as fronteiras romenobúlgaras no Tratado de Neuilly" (Erber, 2013, p. 24), mas que apenas viajava através do álcool e, finalmente, como oportunidade para Ciprian.

Com a saída da Romênia do protagonista - que, no final dos anos 1980 "sonhava em sair de Bucareste em grande estilo" (Erber, 2013, p. 47) -, tem início um momento de abertura do olhar, integrado na formação do protagonista como artista, que substitui a tradicional e passadista viagem à Itália ou ao Oriente por um longo périplo pela Europa. Nesse romance que entrelaça dois olhares, o da existência e o da criação, Ciprian transita por paisagens sociais e artísticas diversas, como Moldávia, Polônia e Eslovênia, países onde realiza as primeiras intervenções em bibliotecas, ou Alemanha e Suécia, onde mora graças a diversos programas de residência para artistas - e podemos lembrar, nesse sentido, que a própria Erber já esteve em residências artísticas na França, Alemanha, Bélgica ou Cuba. Nesses 
lugares, o protagonista conhece gênios e operários da arte que familiarizam progressivamente o leitor com o lugar-comum da crise da arte contemporânea, agora focada a partir da perspectiva não do público, mas, de modo inovador, do protagonista e dos outros artistas, curadores e intelectuais desencantados com o que Ciprian coabita e trabalha.

Numa época em que, como nos diz Marc Augé, as retóricas intermediárias se degradam e desorganizam, a elaboração individual de representações do mundo deve ser seriamente considerada (Augé, 2014, p. 134). É assim que ocorre no romance de Erber, através do olhar de Ciprian e alguns outros artistas, libertos de obrigações de escola, que, sem esquecer que hoje o papel do crítico ou do curador tem, às vezes e apesar da sua fragilidade, mais destaque que o do próprio artista, assumem também esse papel como intelectuais bifrontes.

Assim, na qualidade de criadores, os artistas parecem evoluir a partir da negação das "grandes verdades" e princípios da arte, como o faziam os poetas "real visceralistas" do chileno Roberto Bolaño. Aqueles poetas de estirpe surrealista que, em Los detectives salvajes, caminhavam para trás, como nos explica uma das personagens, "de costas, olhando um ponto, mas distanciando-nos dele, em linha reta rumo ao desconhecido" (Bolaño, 2007 , p. 17, tradução nossa), sempre atentos ao ponto de ruptura, pois é aí que estava a chave da sua (r)evolução.

Associa-se a isso a assunção de um discurso crítico próprio e individual, gerado ad hoc pelos diversos artistas que vamos conhecendo, nos variados décors em que o protagonista fica e que falam constantemente da atualidade artística. Sob esse ponto de vista, o romance apresenta uma erudição ostentosa e atualizadíssima - a respeito de artistas, críticos, realizadores ou escritores - e, mesmo assim, o tom não é nunca pomposo ou grandiloquente, por causa do escasso conformismo, que representa um elo de união entre todos eles.

Erber julga, assim, a arte, a literatura e o cinema contemporâneos através desse mosaico de personagens ligadas ao campo cultural, confrontando-os sem temor ou timidez e questionando-os com pleno conhecimento de causa. A autora capta com maestria em sua obra o "espírito do tempo", a percepção generalizada de que existe uma crise em progresso, ecoando a crescente sensação de desassossego, incerteza, descontentamento e frustração e contrapondo-a a uma certa autocomplacência ainda existente no campo cultural e que permite manter a miragem do progresso e da pujança do sistema. 
Essa provocadora autoindulgência é interpretada sem ironia - o contentamento irônico parece provir do olhar de um narrador ambiguamente mordaz -, entre outros, por Miki, a artista japonesa que propunha uma classificação totalizadora para a arte, dividida em oito categorias, "que se incluía entre os neotrágicos existencial-conceitualistas, mas que não tinha a coragem destrutiva dos artistas que admirava" (Erber, 2013 , p. 70) e que, por esse comedimento artístico, podia ser confundida, sentada na areia da praia, com "uma pessoa entristecida, mas era uma mulher contemporânea em pleno exercício de sua arte" (Erber, 2013, p. 71).

Como se pode verificar nesse exemplo, a autoindulgência e a paradoxal procura de novos e grandes discursos legitimadores, dubiamente expostas pelo narrador, têm um considerável poder reativo, causando no leitor a necessidade de ponderar quantas dessas ideias e propostas são realmente novas, originais, transgressoras, geniais ou, no mínimo, clarividentes a ponto de poderem "substituir" a arte anterior e os princípios analíticos da história da arte.

Para retratar essa dualidade do panorama cultural, pessimista e, ao mesmo tempo, contraditoriamente ufanista, a obra adota, como já visto, uma estrutura interrogativa, articulada em torno de problemas candentes e questões que assumem uma importância crucial nessa radiografia do mundo artístico. Isso ocorre, quando se pergunta, por exemplo: "com quantos bons projetos se faz um artista?" (Erber, 2013, p. 54); "o mercado estimula ou deturpa a criação artística?"; ou "de quantos sapatos precisa um artista em trânsito?" (Erber, 2013, p. 116).

Como dizíamos no início deste texto, Erber opta pela resposta provisória que intensifica a pergunta, ou seja, pela resposta interrogativa de que falava Maurice Blanchot como princípio compositivo e, consequentemente, no romance não temos uma resposta cabal, perfeita e acabada às questões levantadas. Para exemplificar isso, podemos pensar nas duas respostas possíveis à segunda questão referida, evidenciadas, respectivamente, pelo ceramista que, graças à sua grandíssima habilidade artística, acaba por dedicar-se à construção de piscinas para os oligarcas árabes, e pela escultora argentina que vendia suas peças às "noivinhas da alta aristocracia" que "também ostentavam luxo e simulacro", sem que, no entanto, o valor mercantil prejudicasse o valor estético e sem que sua obra, consequentemente, perdesse sua relevância, graças à sua "habilidade escultórica" "impressionante" (Erber, 2013, p. 72). 
Se pensarmos já na última questão, percebemos que é exatamente isso que Ciprian é: um artista em trânsito, o paradigma da potencial vítima da possível obsolescência e esgotamento do atual sistema da arte, simbolizada através da distorção da viagem em trânsito.

Trata-se de uma experiência de estranhamento artístico, semelhante à experimentada por outras personagens da literatura brasileira contemporânea. Em Esquilos de Pavlov, o olhar sensível do artista distancia a viagem do simples turismo - presente, por exemplo, no beletrismo do louvor a Praga presente em O livro de Praga (2011), de Sérgio Sant'Anna. Erber nega essa modalidade e opta por construir um périplo-outro, como Bernardo Carvalho, em O sol se põe em São Paulo, ou Chico Buarque, em Budapeste, em torno do deslocamento, da descoberta, do choque e/ou da aflição.

Nesse caso, Erber projeta seu artista "em formação" num tempo dilatado e errático - do ponto de vista existencial e criativo -, ao tornar as diversas cidades e residências por onde Ciprian passa espaços próximos dos não lugares da pós-modernidade (Augé, 2014, p. 157), na medida em que são apresentados como espaços de transitoriedade. Do ponto de vista antropológico, trata-se de ambientes com maior consistência do que estradas e aeroportos- isto é, são lugares identitários, sociais e históricos -, mas que provocam atitudes e relações com o mundo semelhantes, pois o sujeito não se compromete muito com eles - lembremos, nesse sentido, que um exemplo dos não lugares paradigmáticos são os espaços laborais, nos quais o sujeito apenas realiza seu trabalho de modo mecânico.

$\mathrm{Na}$ passagem de uma residência para outra, o protagonista segue à deriva, num percurso acidentado, em que a inércia da procura e da insatisfação adia qualquer possibilidade de encontro, de resolução, pois, como diz o protagonista:

Não sei quando nem exatamente por que comecei a sentir que estava me desperdiçando em bolhas provisórias, adiando mais um pouco o momento de cair no limbo onde tudo é possível, inclusive a morte ou o amor. Então de novo, um novo lugar, com uma bolsa mais ou menos generosa, em geral rala (Erber, 2013, p. 58).

Como se pode observar, a viagem, apesar de perder seu sentido e afastar o sujeito de seu itinerário inicial - a conquista de um espaço próprio dentro do mundo da arte contemporânea -, continua a ser entendida como aquilo que transfigura nosso estar no mundo e estimula a reflexão e a interrogação. É assim, que o protagonista chega 
a uma conclusão profundamente inquietante: o deslocamento físico não implica a ansiada evasão mental e espiritual, trata-se de uma tentativa vazia, que não estimula o contato com o ser - que, aliás, renova - e que, portanto, é oposta à experiência plena, tal como concebida por Maurice Blanchot ou por Michel Foucault. A insatisfação acompanha Ciprian em cada viagem, do mesmo modo que acontecia a um dos protagonistas do polifônico e lúcido relato de Alain de Botton sobre a poética da viagem, realizado a partir de uma incomum experiência num aeroporto, onde ele foi convidado e "pomposamente denominado como o primeiro escritor-residente de Heathrow" (Botton, 2009, p. 52). Assim, o escritor suíço, ele próprio tornado um excêntrico artista em trânsito, destacava, como mostra da aporia contida no princípio de evasão, o exemplo de David, turista casado e com filhos que, antecipando a satisfação da viagem, tinha pensado muito na sua planejada estadia no Peloponeso, mas, já no aeroporto, chegou a uma conclusão inesperada e perturbadora: que estava trazendo a si próprio para aquelas férias (Botton, 2009, p. 52).

Nesse caso, a reflexão de Erber foca, através da impossibilidade da renovação - marcada pela presença constante da consciência insatisfeita de Ciprian, que leva a si mesmo em todas as viagens, aprofundando cada vez mais o vazio - a própria deturpação do cosmopolitismo de que o protagonista participa através de uma itinerância que se tornou um "coquetel de atrações" (Erber, 2013, p. 121). Isto é, das relações e da pobre mundividência que se estabelecem a partir da experiência de um mapamúndi de viagens organizadas, de residências, bienais e feiras:

No crepúsculo do modernismo, os artistas trabalhavam intensamente em seus ateliês, frequentemente sozinhos e isolados, sofrendo todo tipo de privações, até serem finalmente descobertos por um art dealer, curador, crítico ou mecenas. O sofrimento artístico não desapareceu, mas tem nos dias de hoje uma forma bastante diferente. Artistas profissionais, egressos de institutos e escolas de arte, passam pouco tempo dentro dos ateliês, vivem uma vida nômade, de aeroporto em aeroporto, recuperando-se de jet lags (Erber, 2013, p. 120).

Essa imagem, diversa da imagem tradicional do artista, do gênio criador solitário e às voltas com a penúria material, apresenta-nos também uma circunstância oposta à de Bénédicte, personagem borderline. Pode representar, assim, de modo evocadoramente 
sugestivo, outra volta do parafuso em relação ao tópico da torre de marfim, reformulado agora por meio do referido estranhamento e destituído da convencional solenidade romântica. Bénédicte viaja imaginariamente, como já foi dito, através de um território muito rico em referências e pensamentos. Já no romance, os artistas percorrem enormes distâncias à procura de novos redutos que reforcem a referida e autocomplacente miragem do progresso e da pujança do sistema, que validem as mesmas ideias, tópicos e estereótipos a respeito do que deve ser ou não ser a arte contemporânea, ou seja, que empobreçam o fértil espaço do debate, como bem sintetiza o protagonista ao afirmar: "queremos ser mais provençais e só conseguimos ser provincianos" (Erber, 2013, p. 156).

Como Bénédicte, Ciprian contempla a realidade a partir de suas margens, pois se a primeira saiu do sistema, o segundo resiste nos limites da integração, e essa distância e esse estranhamento que lhes cabe viver a respeito do presente artístico confere-lhes uma incomum lucidez crítica. Ambos os protagonistas possuem um invulgar perfil por meio do qual são capazes de ponderar com clareza e clarividência o estado das artes. Tal como afirmou Giorgio Agamben, o ser verdadeiramente contemporâneo é aquele que não se ajusta perfeitamente a seu tempo "nem está adequado às suas pretensões e é, portanto, nesse sentido, inatual; mas, exatamente por isso, exatamente através desse deslocamento e desse anacronismo, ele é capaz, mais do que os outros, de perceber e apreender seu tempo" (Agamben, 2009, p. 58).

Nesse impasse criativo, ambas as personagens oscilam entre uma melancolia, por assim dizê-lo, quase vintage e uma depressão cutting edge. Comecemos por analisar esse último polo do eixo imaginário do desassossego. Os dois (prot)agonistas estão à beira da depressão durante grande parte das obras e, se levarmos em conta suas atribulações, é razoável supor que eles, finalmente, "entalarão", pois além de eles próprios serem artistas pós-modernos, são personagens de uma autora que trabalha em sintonia com os nossos tempos. Nesse sentido, como indica Catherine Grenier no ensaio Dépression et subversion, uma das imagens mais fortes e emblemáticas nas produções da arte contemporânea é a da figura do deprimido, representada, por exemplo, no pagliaccio triste de Ugo Rondinone ou no homem só e imóvel absorvido pela natureza de Peter Doig. Trata-se do paradigma do homem contemporâneo, mas também do substituto do artista - 
como nos diz a autora, essa figura paradigmática, que partilha algumas caraterísticas com os nossos dois protagonistas, parcialmente "dessensibilizados", "depsicologizados" e apresentados, não através da tragédia, mas de um modo distanciado e permeado pela ironia, que exprime a recusa do mundo (Grenier, 2004, p. 7). Podemos pensar, a título de exemplo, em Bénédicte, cuja única solução para seu transtorno parece ser a intoxicação farmacológica, que, aliás, é possível intuir a partir das vivas ilustrações no livro de umas pílulas coloridas que, ironicamente, como se nos revela a seguir, são apenas vitaminas.

Erber, por meio de Bénédicte e Ciprian, aproveita a força da reatividade e do estranhamento própria dessa rejeição: são personagens que contestam os fundamentos modernos da vitalidade, da comunicação ou da eficácia, mas não radicalmente, pois eles não adotam a inércia como princípio vital. Não se trata de personagens totalmente abúlicas, pois ainda conservam alguma coisa da atitude consagrada do artista moderno, voluntariamente situado nas margens, mas numa posição de observador crítico ou mesmo de juiz, sombrio e insatisfeito. As histórias de Bénédicte e Ciprian apresentam, antes de tudo, reflexões a respeito da arte, sob uma perspectiva de autor, comentador e crítico de si próprio, mas também da arte do seu tempo. Podemos, portanto, afirmar que Laura Erber aproveita ainda certos elementos de uma das formas de subversão preferidas do pensamento moderno: a melancolia.

No entanto, essas figuras, que não se adaptam totalmente ao novo espírito do tempo - apaticamente pós-moderno no sentido indicado pelo sociólogo e pensador francês Gilles Lipovetsky, quando falava da passividade como traço expressivo do indivíduo contemporâneo -, também não parecem adequados ao zeitgeist passado. Como sabemos, a depressão é uma expressão da democratização da interioridade presente na arte contemporânea, enquanto a melancolia é bem caraterística do gênio singular, do artista com maiúscula, confrontado com a vertigem do mundo. O problema reside não apenas no fato de a teoria do gênio estar passé, senão, principalmente, no fato de nós não sabermos se Bénédicte e Ciprian são artistas excepcionais, e é aqui que reside também a força irônica, estranhada e ambiguamente questionadora dessas obras: se Bénédicte e Ciprian fossem autores deprimidos, essa condição não constituiria um problema, pois a depressão é "igualitária" e pode ser padecida por artistas e artesãos. 
Mas eles se aproximam da melancolia e, consequentemente, o leitor deve determinar se essa atitude é legítima ou melodramática e, portanto, se é mais um dos filtros irônicos através dos quais Erber disseca a arte contemporânea.

Esse dilema afigura-se particular e mordazmente complexo uma vez que, como se lê em Esquilos de Pavlov, ecoando o ditado de Benedetto Croce a respeito da sorte da arte - isto é, que todo mundo sabe perfeitamente o que é, mas ninguém consegue defini-la -, "a maior parte das pessoas nunca teria visto arte se não conhecesse essa palavra" (Erber, 2013, p. 54). Além disso, da pouca confiança no público bem como em sua autoridade e suas faculdades, a complexidade deriva de um segundo obstáculo já referido: a perda de critérios objetivos - isto é, técnicos ou próprios da ars isidoriana, uma vez que submetidos a prévios e convencionais princípios e regras rigorosos - para avaliar a "maestria" dos nossos protagonistas. Explico-me melhor: nós, leitores, não conhecemos de modo rigoroso as criações de Ciprian e Bénédicte, apenas algumas referências às reorganizações de livros nas bibliotecas do primeiro e uma imagem final do filme - "que contém / uma única cena" (Erber, 2011, p. 62) em que Bénédicte representa o mar, novamente limitado a um desenho despojado e perturbadoramente simples.

Perante essas exíguas mostras de sua arte, muito provavelmente, o primeiro pensamento de muitos dos leitores será uma questão, a mesma que, também muito provavelmente, lhes provocou o primeiro contato com os desenhos de Bénédicte vê o mar, isto é, perguntar se eles próprios seriam capazes de fazer isso. Como resposta necessariamente provisória, podemos lembrar as palavras de Francesco Bonami, num ensaio significativamente intitulado Lo potevo fare anch'io: hoje a ideia conta mais do que o gênio técnico e o métier, como acontecia, por exemplo, com a escultura de Canova. Nos nossos dias, o mais importante é pensar e conceber uma ideia artística, genial, subversiva, sendo isso suficiente para que ela se torne arte (Bonami, 2009, p. 12-13).

No entanto, apesar desse esclarecimento, a questão crucial mantém-se, apenas muda levemente sua forma e seu foco: Bénédicte e Ciprian podem ser artistas modernos, mas que tipo de artistas são?

Podem ser grandes artistas com grandes ideias, apesar de aparentemente insensatas ou infantis, como Piero Manzoni, quem, como nos lembra Bonami, metendo fezes numa lata, queria sublinhar que ser 
artista pode significar transformar a própria vida em arte e comprimir a própria miséria. Como, mutatis mutandis, faz com maestria Laura Erber, que comprime todas as censuras, inseguranças, desventuras, fraquezas e imperfeições do artista, gênero a que, não por acaso, ela própria pertence, nas duas histórias de Bénédicte e Ciprian.

Mas eles também podem ser, se me permitem um jogo de palavras, artistas medíocres, ou mesmo artistas de merda, pois, lembremos, ambos não são capazes de comunicar-se com o mundo à sua volta, já que ninguém nas histórias os leva a sério: Bénédicte é expulsa do porão pela sua proprietária, que, rapidamente, "mandou limpar aquele nojo" (Erber, 2011, p. 58) - isto é, os restos da luta visceral de Bénédicte com o livro que tentava escrever. Ciprian, por sua vez, passa de artista emergente mais ou menos reconhecido durante algum tempo - por um círculo, como vimos, de autoridade e princípios duvidosos - a artista esquecido e ignorado pelo mesmo mundo da arte.

Constatamos, portanto, como as duas histórias são movidas por um permanente exercício de procura, além de uma terrível sensação de insegurança: busca agônica de uma forma e de uma inspiração para a criação, no caso de Bénédicte, a artista bloqueada; e procura agônica de um sentido para a criação no campo artístico contemporâneo, no caso de Ciprian, artista insatisfeito, significativamente, não tanto com a própria arte - evocando, talvez levemente a figura da autocomplacência contemporânea -, mas com o mundo da arte.

Trata-se de dois artistas situados, de diferente modo, em conjunturas que evocam a morte da arte hegeliana, entendida como

elemento constituinte da arte moderna, como sacrifício ritual pelo qual a arte renuncia constantemente a sua tradição e a sua autonomia, para restabelecê-las num plano sempre diferente. Toda obra relevante de arte moderna não se põe como a primeira de uma nova fase, mas como a última, aquela além da qual já não se pode ir. [...] a arte moderna mantém sua autoridade porque fala do limiar do mundo dos mortos (Mammì, 2012, p. 23).

E, dessa posição extrema, as ideias e intuições só podem manifestar-se por crises e epifanias. Crises, como as sofridas pelos dois protagonistas e epifanias como a de Ulrikka Pavlov, responsável pela última residência artística em que Ciprian se instala e que, num discurso grandiloquente, propõe a derrelição como princípio artístico aos bolseiros da residência; quer dizer, abandonar a vida artística e a identidade de artistas, abandonar 
"as obrigações desse sistema que não faz mais do que impedir o artista se desenvolver plenamente" com "editais, residências, conferências, jantares com colecionadores", pois tem a certeza de que, com o decorrer do tempo "estarão produzindo as obras mais vitais do novo século, aquelas que fogem a todas as expectativas" (Erber, 2013, p. 122).

Isto é, aquilo que Ulrikka propõe aos presentes é tomar conta do próprio jardim e abandonar a selva do mundo da arte. No caso de Ciprian, a vertigem da viagem e a pulsão de sair do privado, de tornar pública sua obra e de se exprimir perante o público atrasam o processo, mas afinal ele acaba, gradativa e mais ou menos conscientemente, por aceitar o desafio de Ulrikka, que não é senão a teorização daquilo que Bénédicte tinha feito conscientemente. Trata-se da renúncia à acumulação dos condicionantes pavlovianos que ambos armazenaram como os esquilos de uma das citações, de Katherine Mansfield, que abrem o romance: "Minha mente parecia um esquilo. Eu juntava e juntava coisas, e depois as escondia, para quando chegasse um longo inverno" (Erber, 2013, p. 9).

Ciprian fica "chateado" (Erber, 2013, p. 47) quando sua última intervenção numa grande biblioteca é considerada um "fiasco", mas decide fazer intervenções em bibliotecas menores, sem prestígio, sem elogio crítico, renunciando ao interesse de massa indispensável no campo artístico e literário contemporâneo - o das grandes residências, exposições e feiras internacionais.

Ambos acabam por ser, portanto, figuras independentes e silenciosas, que resultam incômodas, incompreensíveis e secretamente revolucionárias, pois a ideia do fracasso implica, no caso das duas obras estudadas, uma crassa simplificação. A aparente derrota de Bénédicte ou Ciprian deriva da determinação de não abdicar, de continuar a tentar e, consequentemente, de falhar mais uma vez num gesto prometeico frustrante, penoso, mas muito mais corajoso que a renúncia, como defende Enrique Vila-Matas, ao criticar a cegueira e a mesquinhez daqueles que ridicularizam de maneira imediatista certas tentativas de inovação artística, pois, em suas palavras,

ocultou-se sempre no fundo um ressentimento, um ódio sujo àqueles que alguma vez tentam arriscar-se procurando fazer alguma coisa nova ou pelo menos diferente; ocultou-se sempre uma aversão doentia em relação àqueles que estão cientes de que, como artistas, estão numa posição privilegiada para fracassar onde os outros não ousariam fazê-lo e por isso tentam criar obras de arte 
arrojadas que não teriam sentido se não envolvessem o fracasso em sua própria essência (Vila-Matas, 2015, p. 46, tradução nossa).

Esse excerto, tirado da obra Kassel no invita a la lógica, sublinha o dualismo de um período que nos oferece uma oportunidade para agir, de modo consciente e mais livre, no real ou optar pela passividade e/ ou ceticismo mais dissolvente e deixar-se levar acriticamente por ela. Contra o cinismo, a tacanhez ou a imediatez nos juízos críticos, o escritor catalão Vila-Matas, convidado ele próprio a realizar uma viagem ao centro da arte contemporânea, como mais um incomum escritor residente - na Documenta de Kassel ele teve por missão tornarse uma instalação viva e sentar-se a escrever num restaurante chinês da cidade -, reflete a respeito da sua própria - e, diga-se de passagem, saudável - suspeita a respeito do atual estado das artes, reintegrando-a em seu discurso como uma distância crítica necessária para ponderar o valor real da proposição de novas ideias que, em termos artísticos, lutem contra a redução do humano e do artístico à irrelevância.

Para tanto, a primeira coisa a fazer é assumir a inegável obsolescência dos valores passados e a indispensabilidade de novas procuras e dos consequentes fracassos, como se afirma em Bénédicte vê o mar, numa adulterada e quase epifânica versão da máxima que afirma que não se deve chorar pelo leite derramado:

acabou chorare
ficou tudo lindo
princípios estéticos tombam
como
lágrimas de um azul
inceleste
no leite gelado (Erber, 2011, p. 23).

O fim desses princípios estéticos derrubados - num sentido distante do iconoclasmo vanguardista que o verbo "tombar" parece evocar - não representa a derrota ou a fraqueza dos novos artistas, mas a consciência de que o andamento de uma crescente deterioração deve ser confrontado - se for possível - com uma transformação significativa do processo criativo e expressivo. Como afirma Juan Antonio Blanco, em sua interessante análise do contexto pós-moderno, habitualmente atribuímos de modo errado ao conceito de crise uma conotação de desfecho unívoco, irreversível e frequentemente trágico. Mas, na verdade, a crise representa apenas uma fase em que a ordem é desestabilizada, constituindo-se, 
portanto, num momento de virada, certamente perigoso e arriscado, pois dele depende a sobrevivência de um sistema ou a evolução para uma existência diversa (Blanco, 1999, p. 30).

Em ambas as obras, esse sacrifício, essa renúncia e esse exercício arriscado são - e nem poderia ser de outra forma - ambiguamente recompensados. Ambos os livros terminam de maneira circular. Bénédicte vê o mar termina com essa mesma frase inicial e também com a mesma imagem desconcertante: o mar do filme da protagonista representa simbolicamente a conquista final da abertura do olhar, um novo horizonte artístico, mas, ironicamente, esse mar também a esmaga (Lemos, 2011, p. 3). Isto é Bénédicte acaba, duvidosamente triunfante, por sacrificar-se pela sua arte, vencendo a pulsão negativa da impossibilidade da criação, da imobilidade artística, a fim de se comunicar com o público e de que nós possamos ver esse mar.

Por sua vez, em Esquilos de Pavlov, Ciprian, ao perder-se no caminho, descobre outros. Através da sua vivência da arte e do campo à sua volta, Ciprian pretendia transmitir certo conhecimento sobre o mundo, mas ele impedia ao seu autor esse conhecimento. Libertado da sua vida de artista em trânsito, ele finalmente parece ter aprendido alguma coisa, a aceitação e a autoaceitação, como, ironicamente, percebe ao ver um corpo num canal e não se deter por falta de tempo:

Não tenho vergonha da minha época, gosto dela, não é épica nem gloriosa, mas gosto dela como de um par de galochas gastas que não se pode abandonar porque apesar de tudo já se acostumavam aos nossos pés, e porque são as únicas que restam, e porque são minhas. Como diz um amigo recente, o mal não está na época, está nalgumas pessoas (Erber, 2013, p. 166).

Além disso, dessa conquista de uma nova consciência que suaviza a fadiga existencial, depois de uma juventude adiada devido às aspirações artísticas, Ciprian é definitivamente ignorado pelo mundo artístico e essa libertação involuntária lhe permite sucumbir ao "amor tardio" (Erber, 2013, p. 167), numa nova e impensada revolta contra o horizonte de espera do leitor contemporâneo - aparentemente concordando com Michel de Montaigne, em que a principal, "grande e mais gloriosa obra-mestra é viver de maneira conveniente" (Montaigne, 2009, III, 13, tradução nossa). Rebelião que, finalmente, nega o distanciamento sarcástico em relação à sublimidade da paixão amorosa, exprimido anteriormente no romance, ao afirmar que "o amor é um 
caminho que se divide: inflacionar a linguagem ou expor sua miséria. Eu te amo, você me ama?" (Erber, 2013, p. 30) ou ao falar de amor, a respeito da relação do protagonista com Pernille, afirmando que "era acreditar na viabilidade prática de uma teoria do impossível" (Erber, 2013, p. 107). Em síntese, o desfecho é uma pequena bomba literária que nos revela que as emoções e os sentimentos românticos ainda podem ou talvez não - ser uma saída ao cinismo narcisista e asséptico que domina esse mundo estranho representado nos textos, pois o romance, com uma grega que vendia tragédias em edições de bolso numa gare em Paris, faz com que o protagonista abandone sua indolência existencial extrema e se/nos pergunte, já adulto, "será que caibo em mim mesmo ou afundo?" (Erber, 2013, p. 167).

Enfim, a melancolia e o ceticismo de seus protagonistas impedem que as histórias se concretizem em histórias de formação à maneira clássica, favorecendo uma escrita de imperfeição deslumbrante e aproveitando o apogeu da interpretação: como sabemos, a pós-modernidade tem se apropriado do aforismo nietzschiano de que não existem fatos, apenas interpretações e, portanto, será o público - esse público formado por alguns membros daquela maioria que nunca teria visto arte se não conhecesse essa palavra, mas também por leitores ideais que partilhem a sofisticada ironia e background cultural da autora - o responsável pela interpretação das obras, que, como podem observar, concluem - não poderia ser de outra forma - com uma sorte de morais ambíguas, à maneira da nietzschiana nihilina, numa irônica abertura que faz pensar na poética presente no extraordinário conto "Os contistas", de Moacyr Scliar, em que o protagonista perde a última página de seu conto, procurando-a incessantemente durante dois dias, até que percebe que o conto fica melhor daquela maneira e abandona a busca.

O leitor é o depositário dessa escrita da irresolução: as obras retratam o crepúsculo ou a ideia de que nunca há tanta obscuridade como antes do amanhecer? Tanto faz, o que importa é que essa sombra perpétua do apocalipse na imaginação artística continua a ser extremadamente fértil.

Nesse sentido - porque pretendemos respeitar as entrelinhas, os interstícios e as aberturas perspicazmente propostos pela autora -, só podemos concluir afirmando que, face aos veneradores do agônico, as obras não são totalmente apocalíticas, mas, sim, desconcertantemente questionadoras, pois supõem uma subversão aplicada à subversão 
mesma, a da pós-modernidade, que radiografa e desconstrói todas as convenções e grandes certezas - mesmo que essas certezas tenham a ver apenas com aquilo que a arte já não pode ser e/ou, paradoxalmente, com a incomensurabilidade daquilo que pode ser - através dessa dúvida com que iniciávamos estas digressivas páginas.

\section{Referências}

AGAMBEN, Giorgio (2009). O que é o contemporâneo? E outros ensaios. Chapecó: Argos.

AUGÉ, Marc (2014). Pour une anthropologie des mondes contemporains. Paris: Flammarion. (Coleção Champs essais).

BLANCHOT, Maurice (1999). La escritura del desastre. Caracas: Monte Ávila.

BLANCO, Juan Antonio (1999). Tercer milenio: una visión alternativa de la posmodernidad. Tafalla: Txalaparta.

BOLAÑO, Roberto (2007). Los detectives salvajes. 13 ed. Barcelona: Anagrama. (Coleção Compactos, n. 232).

BONAMI, Francesco (2009). Lo potevo fare anch'io: perché l'arte contemporanea è davvero arte. Milano: Mondadori. (Coleção Piccola Biblioteca Oscar Mondadori).

BONAMI, Francesco (2013). Mamma voglio fare l'artista!: istruzioni per evitare delusioni. Milano: Mondadori Electa.

BOSI, Alfredo (2002). Literatura e resistência. São Paulo: Companhia das Letras.

BOTTON, Alain de (2009). Uma semana no aeroporto: um diário de Heathrow. Alfragide: Dom Quixote.

COMPAGNON, Antoine (1979). La seconde main ou le travail de la citation. Paris: Seuil.

ERBER, Laura (2011). Bénédicte vê o mar. Jaraguá do Sul: Editora da Casa.

ERBER, Laura (2013). Esquilos de Pavlov. Rio de Janeiro: Alfaguara.

GINZBURG, Jaime (2012). O narrador na literatura brasileira contemporânea. Tintas. Quaderni di letterature iberiche e iberoamericane, Milano, n. 2, p. 199-221, nov.

GRENIER, Catherine (2004). Dépression et subversion: les racines de l'avantgarde. Paris: Centre Pompidou. 
HUTCHEON, Linda (1984). Narcissistic narrative: the metafictional paradox. New York: Methuen.

JOUANNAIS, Jean-Ives (2009). Artistes sans oeuvres: I would prefer not to. Nouvelle édition augmentée d'une préface d'Enrique Vila-Matas. Paris: Gallimard.

LEMOS, Masé (2011). Experimentações literárias em formato digital. O Globo, Rio de Janeiro, caderno Prosa E verso, p. 3, 15 out.

MAMMİ, Lorenzo (2012). O que resta: arte e crítica de arte. São Paulo: Companhia das Letras.

MONTAIGNE, Michel de (2009). Les essais. Edição de André Lanly. Paris: Gallimard.

PERRONE-MOISÉS, Leyla (2012). A literatura exigente. Folha de S. Paulo, São Paulo, caderno Ilustríssima, p. 4-5, 25 mar.

VILA-MATAS, Enrique (2015). Kassel no invita a la lógica. Barcelona: Seix Barral. (Coleção Booket, n. 2.641).

Recebido em fevereiro de 2016.

Aprovado em junho de 2016.

\section{resumo/abstract/resumen}

\section{A ultrapassagem das fronteiras: hibridismo e universalismo na obra de Laura Erber}

Alva Martínez Teireixo

Este artigo analisa duas das obras literárias da escritora, artista visual e professora Laura Erber, explorando o convívio na sua escrita de algumas tendências caraterísticas da literatura brasileira pós-moderna, como o hibridismo genérico, os diálogos interartísticos, o protagonismo da dimensão metaficcional ou a atualização da escrita do eu e do tema literário da viagem. $\mathrm{O}$ trabalho parte, assim, da análise de Bénédicte vê o mar (2011), pequeno e poético romance gráfico ou, melhor, poemário gráfico, e Esquilos de Pavlov (2013), atípico "romance de artista". Trata-se de duas obras dotadas de uma liberdade de tom admirável e de uma compreensão profunda dos desafios literários contemporâneos, postas ao serviço de um pensamento questionador em que se entrecruzam dois olhares: o da existência e o da criação artística. Nesse sentido, examina-se como o protagonismo da questão da crise da arte contemporânea na literatura, no cinema e nas artes plásticas - permite à autora estabelecer um 
diálogo cultural que ultrapassa as fronteiras do nacional para situar-se num plano mais abrangente.

Palavras-chave: literatura pós-moderna, hibridismo, interartes, Laura Erber.

\section{Crossing borders: hybridity and universalism in the work of Laura Erber}

\section{Alva Martínez Teireixo}

This article examines two literary works by the writer, visual artist and educator Laura Erber, exploring the coexistence in her writing of certain trends of postmodern Brazilian literature, such as hybrid textual genres, inter-artistic dialogues, the foregrounding of a metafictional dimension, or new ways of writing the self and of the literary theme of travel. This essay therefore starts with an analysis of Bénédicte vê o mar (2011), a short, graphic, poetic romance, or rather graphic book of verse, and Esquilos de Pavlov (2013), an atypical "artist's romance". These two works are endowed with an admirable freedom of expression and a deep understanding of the challenges that contemporary literary writing faces. These facets, in turn, serve to generate a critical interrogation that intertwines two themes: being and artistic creation. This article therefore examines how the crisis of contemporary art: in literature, film and the visual arts - allows the author to establish a cultural dialogue that transcends the boundaries of the national to encompass a broader context.

Keywords: postmodern literature, hybridity, inter-art, Laura Erber.

\section{La superación de las fronteras: hibridismo y universalidad en la obra de Laura Erber}

Alva Martínez Teireixo

Este artículo analiza dos de las obras literarias de la escritora, artista visual y profesora Laura Erber, investigando la convivencia en su obra de algunas tendencias características de la literatura brasileña posmoderna, como el hibridismo genérico, los diálogos interartísticos, el protagonismo de la dimensión metaficcional o la actualización de la escritura del yo y del tema literario del viaje. El trabajo parte, así, del análisis de Bénédicte vê o mar (2011), pequeña y poética novela gráfica, o, mejor dicho, poemario gráfico, y Esquilos de Pavlov (2013), atípica "novela de artista". Se trata de dos obras dotadas de una libertad de tono admirable y de una comprensión profunda de los desafíos literarios contemporáneos, puestas al servicio de un pensamiento crítico en el cual se entremezclan dos visiones: la de la existencia y la de la creación artística. Así, se pretende examinar cómo el protagonismo de la cuestión de la crisis del 
arte contemporáneo -en la literatura, el cine y las artes plásticas- permite a la autora establecer un diálogo cultural que traspasa las fronteras de lo nacional para situarse en un plano más abarcador.

Palabras clave: literatura posmoderna, hibiridismo, interartes, Laura Erber. 